\title{
Factors favouring long-term survival following recurrence in ovarian cancer
}

\author{
HIROAKI SOYAMA ${ }^{1}$, MASASHI TAKANO ${ }^{2}$, MORIKAZU MIYAMOTO $^{1}$, TOMOYUKI YOSHIKAWA ${ }^{2}$, \\ TADASHI AOYAMA ${ }^{1}$, TOMOKO GOTO ${ }^{1}$, JUNKO HIRATA ${ }^{1}$, AYAKO SUZUKI ${ }^{1}$, \\ HIDENORI SASA ${ }^{1}$ and KENICHI FURUYA ${ }^{1}$ \\ Departments of ${ }^{1}$ Obstetrics and Gynecology and ${ }^{2}$ Clinical Oncology, National Defense \\ Medical College Hospital, Tokorozawa, Saitama 359-8513, Japan
}

Received August 17, 2016; Accepted March 6, 2017

DOI: $10.3892 / \operatorname{mco} .2017 .1266$

\begin{abstract}
The aim of the present study was to identify clinicopathological factors in long-term survivors following ovarian cancer recurrence. The patients who achieved longer survival after recurrence $(n=18)$ and those who succumbed to the disease earlier $(n=47)$ were identified and analyzed. There were no significant differences in age, performance status, stage distribution or histology between the two groups. Additionally, no significant difference was observed in progression-free survival after primary therapy. Multivariate analyses revealed that the predictive factors for long-term survival were i) secondary debulking surgery (OR=13.3; 95\% CI: 1.39-226.7), ii) favourable response rate of second-line chemotherapy (OR=46.5; 95\% CI: 1.84-313-4), and iii) $\geq 3$ regimens after first recurrence $(\mathrm{OR}=9.01 ; 95 \% \mathrm{CI}: 1.28-117.7)$. This study revealed that prolonged post-progression survival was associated with post-recurrence treatment. Therefore, appropriate selection of secondary debulking surgery and better chemotherapeutic response may lead to prolonged post-progression survival in recurrent ovarian cancer patients.
\end{abstract}

\section{Introduction}

The median post-progression survival (PPS) for ovarian cancer patients is $\sim 2$ years (1). Ovarian cancer is a well-known chemosensitive malignancy. However, once the cancer relapses, it may be difficult to treat (1). Although a proportion of the patients achieve long-term PPS, the determining clinicopathological factors have yet to be fully elucidated.

It is considered that longer progression-free survival (PFS) may prolong overall survival (OS) based on the theory of

Correspondence to: Dr Masashi Takano, Department of Clinical Oncology, National Defense Medical College Hospital, 3-2 Namiki, Tokorozawa, Saitama 359-8513, Japan

E-mail: mastkn@ndmc.ac.jp

Key words: ovarian cancer, recurrence, chemotherapy, secondary debulking surgery, overall survival, post-progression survival reducing the number of cells available for subsequent mutation (2). Another study reported that the time-to-relapse is the most important prognostic factor in ovarian cancer, as subsequent chemotherapy regimens and the response to subsequent chemotherapy are determined based on this time interval (3). It was previously reported that secondary debulking surgery (SDS) was an effective treatment for recurrent ovarian carcinoma; however, the criteria for selecting SDS candidates remain unclear (4).

In the present study, the clinicopathological characteristics of patients achieving a longer PPS were analyzed in comparison with those of patients who succumbed to the disease earlier.

\section{Patients and methods}

Patient selection. Among patients with ovarian cancer who underwent first-line therapy between 1995 and 2006, those who developed relapse until the end of 2012 at the National Defense Medical College Hospital (Tokorozawa, Japan) were enrolled in the present study. The patients who achieved a 5-year PPS after the first recurrence or progression were defined as long-term survivors (LS), whereas those who succumbed to relapsed ovarian cancer within 5 years after the first recurrence or progression were defined as short-term survivors (SS). The patients who succumbed to other diseases and those with insufficient follow-up data were excluded (Fig. 1). The aim of this study was to identify differences in the clinicopathological characteristics between LS and SS based on the data acquired until the end of 2012.

Survival. In this study, OS was defined as the time from initial diagnosis of the disease to death, and PFS was defined as the time from initial diagnosis of the disease to diagnosis of clinical relapse, progression, or death. PPS was measured from the time of the first recurrence or progression to death. Platinum-free interval (PFI) was defined as the time between the end of the platinum-based chemotherapy and the first occurrence of relapse.

Treatment and follow-up. The patients were classified based on the International Federation of Gynecology and Obstetrics (FIGO) 1988 stage classification. Primary therapy included 
primary debulking surgery + adjuvant chemotherapy, neoadjuvant chemotherapy + interval debulking surgery, and first-line chemotherapy alone for inoperable patients. All the patients received platinum agents as first-line or adjuvant chemotherapy. SDS was only considered for patients whose identified recurrent tumors were expected to be completely resectable based on the clinician's discretion. For follow-up, physical and sonography examinations with carbohydrate antigen 125 (CA125) levels were evaluated every 3 months for 2 years. After 2 years, these examinations were performed every 3-6 months for at least 5 years. Computed tomography images were routinely checked every 6-12 months, or when the examinations raised the suspicion of recurrence. The Response Evaluation Criteria in Solid Tumors (RECIST), version 1.1 (5) was used to evaluate the effectiveness of the treatment. The Gynecologic Cancer Intergroup CA125 criteria were not used for diagnosis of recurrence (6). Performance status (PS) was evaluated based on the Eastern Cooperative Oncology Group (ECOG) PS system.

The clinical variables evaluated were as follows: Age at primary therapy, PS at primary therapy, FIGO stage, histology, residual tumor (RT) after primary therapy, $\mathrm{PFI}$, age at recurrence, PS at recurrence, recurrent site, SDS, second-line chemotherapy regimens, response to second-line chemotherapy and number of chemotherapy regimens after the first recurrence.

Statistical analysis. Statistical analysis was performed using the JMP 10.0.0 software package (SAS Institute, Inc., Tokyo, Japan). The $\chi^{2}$ test and Mann-Whitney $\mathrm{U}$ test were used to evaluate differences in patient characteristics. Multivariable analyses were based on the logistic regression method and Kaplan-Meier survival curves of OS, PFS and PPS were compared using the log-rank test. Statistical significance was defined as $\mathrm{P}<0.05$.

This study was approved by the Institutional Review Board of the National Defense Medical College.

\section{Results}

Patient characteristics. Among a total of 120 patients with ovarian cancer, 86 developed relapse, of whom 21 patients were excluded from the present study ( 2 patients succumbed to another disease and data were insufficient for 19 patients). Finally, 65 patients met the inclusion criteria and were enrolled in the study: 18 patients $(28 \%)$ were classified as LS and 47 patients $(72 \%)$ as SS (Fig. 1).

Patient survival. Kaplan-Meier survival curves for OS, PFS and PPS are presented in Fig. 2. The median PPS in LS and SS was 82.5 months (range, 60-122 months) and 15 months (range, 3-59 months), respectively ( $\mathrm{P}<0.01$, Fig. 2A). The median OS was 102.5 months in LS (range, 71-162 months) and 31 months in SS (range, 4-123 months) ( $\mathrm{P}<0.01$, Fig. 2B). In addition, the median PFS after primary therapy in LS and SS was 15.5 months (range, 71-162 months) and 4 months (range, 1-91 months), respectively ( $\mathrm{P}=0.055$, Fig. $2 \mathrm{C})$.

Patient characteristics. The clinicopathological characteristics of the patients are summarized in Table I. Significant differences between the two groups included RT after primary therapy $(\mathrm{P}<0.01), \mathrm{PFI}(\mathrm{P}=0.01), \mathrm{PS}$ at recurrence $(\mathrm{P}<0.01), \mathrm{SDS}(\mathrm{P}=0.03)$ and favourable response to second-line chemotherapy $(\mathrm{P}<0.01)$.

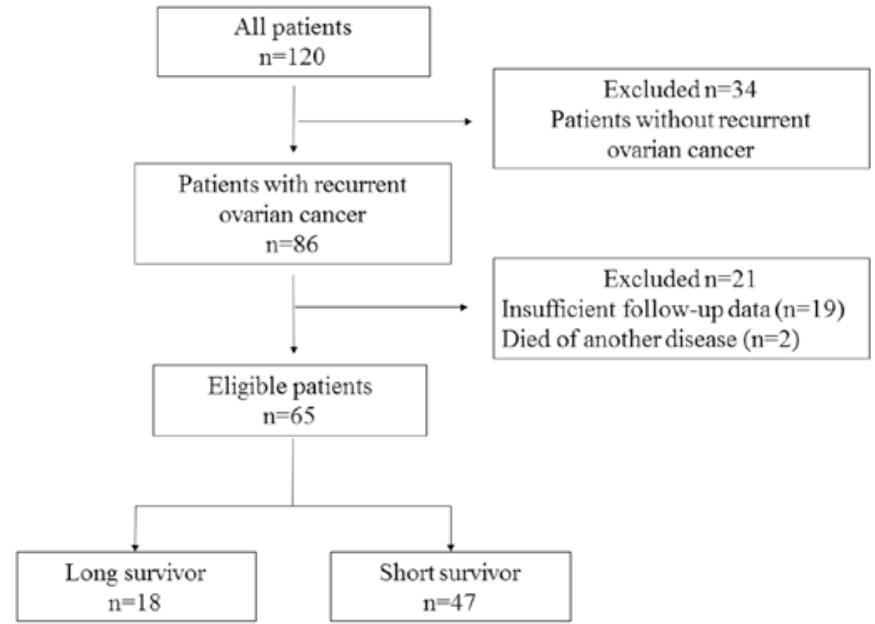

Figure 1. Flow chart of the patient selection process.
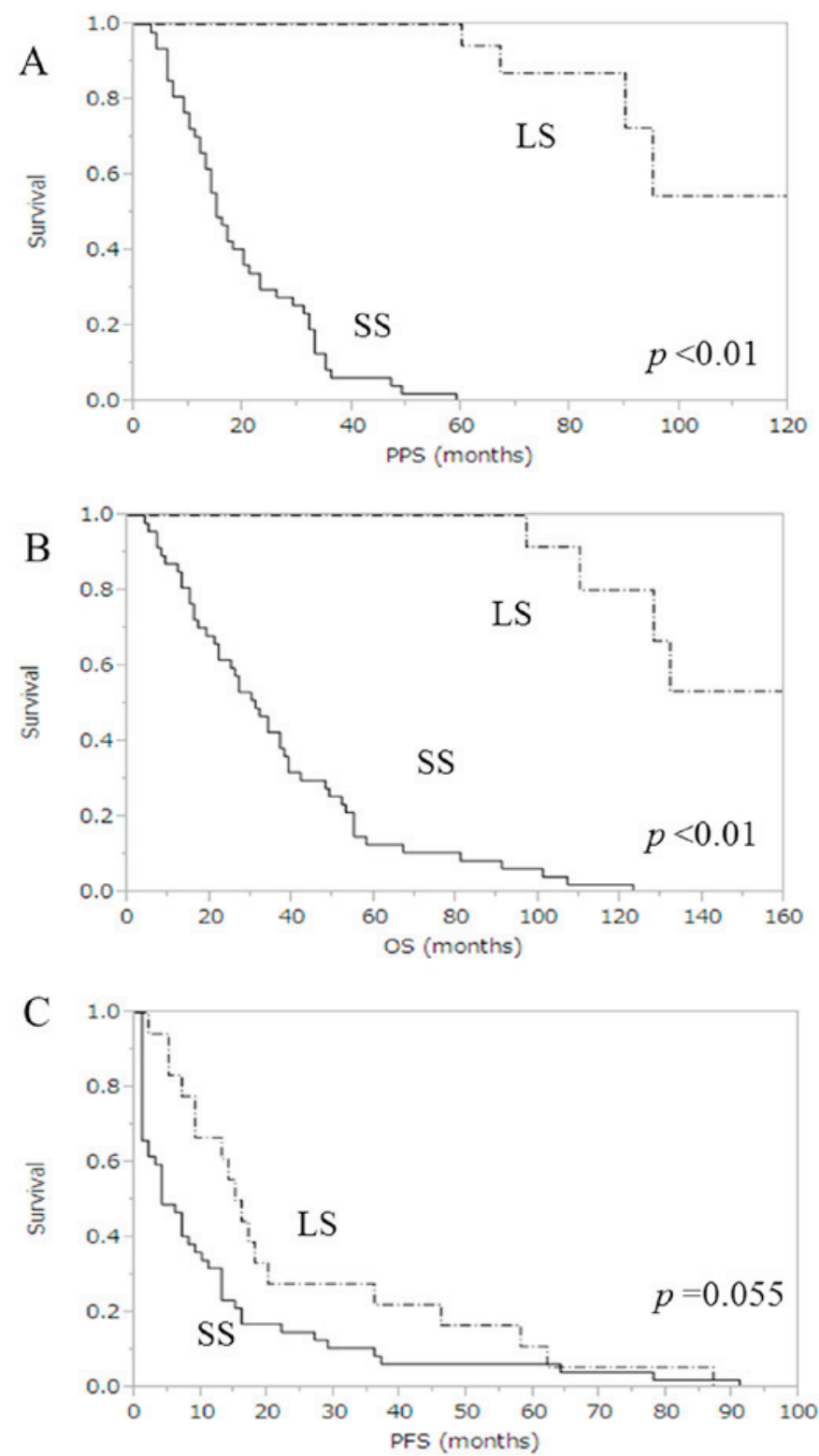

Figure 2. Kaplan-Meier survival curves of the patients. (A) Post-progression survival (PPS) curves of long-term survivors (LS) and short-term survivors (SS). (B) Overall survival (OS) curves of LS and SS. (C) Progression-free survival (PFS) curves of LS and SS. 
Table I. Characteristics of the patients $(n=65)$.

\begin{tabular}{|c|c|c|c|}
\hline \multirow[b]{2}{*}{ Characteristics } & \multirow{2}{*}{$\begin{array}{c}\begin{array}{c}\text { Long-term } \\
\text { survivors, } \mathrm{n}(\%)\end{array} \\
(\mathrm{n}=18)\end{array}$} & \multirow{2}{*}{$\begin{array}{c}\text { Short-term } \\
\text { survivors, } \mathrm{n}(\%) \\
(\mathrm{n}=47)\end{array}$} & \multirow[b]{2}{*}{ P-value } \\
\hline & & & \\
\hline \multicolumn{4}{|c|}{ Age at primary therapy (years) } \\
\hline$\leq 54$ & $12(67)$ & $20(43)$ & 0.08 \\
\hline$>54$ & $6(33)$ & $27(57)$ & \\
\hline \multicolumn{4}{|l|}{ PS at primary therapy } \\
\hline 0 & $12(67)$ & $30(64)$ & 0.83 \\
\hline$\geq 1$ & $6(33)$ & $17(36)$ & \\
\hline \multicolumn{4}{|l|}{ FIGO stage } \\
\hline I & $5(28)$ & $7(15)$ & 0.23 \\
\hline II-IV & $13(72)$ & $40(85)$ & \\
\hline \multicolumn{4}{|l|}{ Histology } \\
\hline Serous & $6(33)$ & $18(38)$ & 0.14 \\
\hline Others & $12(67)$ & $29(62)$ & \\
\hline \multicolumn{4}{|c|}{ RT after primary therapy } \\
\hline Yes & $1(6)$ & $20(43)$ & $<0.01$ \\
\hline No & $17(94)$ & $27(57)$ & \\
\hline \multicolumn{4}{|c|}{ PFI at first recurrence (months) } \\
\hline$<6$ & $3(17)$ & $24(51)$ & 0.01 \\
\hline$\geq 6$ & $15(83)$ & $23(49)$ & \\
\hline \multicolumn{4}{|c|}{ Age at first recurrence (years) } \\
\hline$\leq 57$ & $11(61)$ & $21(45)$ & 0.23 \\
\hline$>57$ & $7(39)$ & $26(55)$ & \\
\hline \multicolumn{4}{|l|}{ PS at first recurrence } \\
\hline 0 & $17(94)$ & $27(57)$ & $<0.01$ \\
\hline$\geq 1$ & $1(6)$ & $20(43)$ & \\
\hline \multicolumn{4}{|l|}{ Recurrent site } \\
\hline Distant metastasis & $4(22)$ & $7(15)$ & 0.48 \\
\hline Others & $14(78)$ & $40(85)$ & \\
\hline \multicolumn{4}{|c|}{ Secondary debulking surgery } \\
\hline Yes & $6(33)$ & $5(11)$ & 0.03 \\
\hline No & $12(67)$ & $42(89)$ & \\
\hline \multicolumn{4}{|c|}{ Second-line chemotherapy } \\
\hline Platinum-based & $16(89)$ & $35(74)$ & 0.18 \\
\hline Others & $2(11)$ & $12(26)$ & \\
\hline \multicolumn{4}{|c|}{ Response to second-line chemotherapy } \\
\hline $\mathrm{CR} / \mathrm{PR}$ & $8(44)$ & $5(11)$ & $<0.01$ \\
\hline $\mathrm{SD} / \mathrm{PD}$ & $10(56)$ & $42(89)$ & \\
\hline \multicolumn{4}{|c|}{ Number of regimens after the first recurrence } \\
\hline$\leq 2$ & $8(44)$ & $31(66)$ & 0.11 \\
\hline$\geq 3$ & $10(56)$ & $16(34)$ & \\
\hline
\end{tabular}

PS, performance status; FIGO, International Federation of Gynecology and Obstetrics; RT, residual tumor; PFI, platinum-free interval; CR, complete response; PR, partial response; $\mathrm{SD}$, stable disease; $\mathrm{PD}$, progressive disease.

By multivariate analysis, SDS (OR=13.3; 95\% CI: 1.39-226.7), favourable response to second-line chemotherapy $(\mathrm{OR}=16.5$; 95\% CI: 1.84-313.4) and receiving $\geq 3$ regimens after the first recurrence (OR=9.01; 95\% CI: $1.28-117.7)$ were identified as factors associated with long-term PPS (Table II).

\section{Discussion}

Recent studies reported that PFS is not associated with OS, particularly in patients with advanced ovarian cancer $(2,7,8)$. Shimokawa et al suggested that PPS rather than PFS was more 
Table II. Multivariate analysis for predictive factors of long-term survivors.

\begin{tabular}{|c|c|c|c|}
\hline Variables & OR & $95 \% \mathrm{CI}$ & P-value \\
\hline \multicolumn{4}{|c|}{ Age at primary therapy (years) } \\
\hline$\leq 54$ & 2.44 & $0.18-45.5$ & 0.50 \\
\hline$>54$ & 1 & & \\
\hline \multicolumn{4}{|l|}{ PS at primary therapy } \\
\hline 0 & 1.30 & $0.19-11.0$ & 0.79 \\
\hline$\geq 1$ & 1 & & \\
\hline \multicolumn{4}{|l|}{ FIGO stage } \\
\hline I & 9.69 & $0.87-168.6$ & 0.07 \\
\hline II-IV & 1 & & \\
\hline \multicolumn{4}{|l|}{ Histology } \\
\hline Serous & 8.11 & $0.99-105.8$ & 0.06 \\
\hline Others & 1 & & \\
\hline \multicolumn{4}{|c|}{ RT after primary therapy } \\
\hline Yes & 0.53 & $0.02-6.98$ & 0.64 \\
\hline No & 1 & & \\
\hline \multicolumn{4}{|c|}{ PFI at first recurrence (months) } \\
\hline$<6$ & 0.32 & $0.03-2.45$ & 0.33 \\
\hline$\geq 6$ & 1 & & \\
\hline \multicolumn{4}{|c|}{ Age at first recurrence (years) } \\
\hline$\leq 57$ & 1.05 & $0.05-17.6$ & 0.97 \\
\hline$>57$ & 1 & & \\
\hline \multicolumn{4}{|l|}{ PS at first recurrence } \\
\hline 0 & 2.36 & $0.23-58.6$ & 0.49 \\
\hline$\geq 1$ & 1 & & \\
\hline \multicolumn{4}{|l|}{ Recurrent site } \\
\hline Distant metastasis & 2.85 & $0.31-33.7$ & 0.35 \\
\hline Others & 1 & & \\
\hline \multicolumn{4}{|c|}{ Secondary debulking surgery } \\
\hline Yes & 13.3 & $1.39-226.7$ & 0.03 \\
\hline No & 1 & & \\
\hline \multicolumn{4}{|c|}{ Second-line chemotherapy } \\
\hline Platinum-based & 3.68 & $0.40-57.2$ & 0.26 \\
\hline Others & 1 & & \\
\hline \multicolumn{4}{|c|}{ Response to second-line chemotherapy } \\
\hline $\mathrm{CR} / \mathrm{PR}$ & 16.5 & $1.84-313.4$ & 0.01 \\
\hline $\mathrm{SD} / \mathrm{PD}$ & 1 & & \\
\hline \multicolumn{4}{|c|}{ Number of regimens after the first recurrence } \\
\hline$\geq 3$ & 9.01 & $1.28-117.7$ & 0.03 \\
\hline$\leq 2$ & 1 & & \\
\hline
\end{tabular}

PS, performance states; FIGO, International Federation of Gynecology and Obstetrics; RT, residual tumor; PFI, platinum-free interval; $\mathrm{OR}$, odds ratio; CI, confidence interval; CR, complete response; PR, partial response; SD, stable disease; PD, progressive disease.

significantly associated with OS (7). Additionally, another study reported that percentage gains in PFS are not associated with percentage gains in PPS (2). Our study also suggested that PFS was not associated with PPS. For this reason, although primary therapy for ovarian cancer is important, appropriate treatment after relapse may be more important for improving OS, in addition to prolonging PPS of ovarian cancer patients.
In the present study, SDS was significantly associated with LS after recurrence. The effectiveness of SDS has been long discussed, not only for platinum-sensitive, but also platinum-resistant recurrence (9-12). Some studies achieved long median OS (>50 months) after recurrence $(11,12)$. However, the criteria for SDS candidacy have not fully established; therefore, the benefit of surgery for patients with relapsed 
ovarian cancer may be limited (13). Recently, selection criteria for operable patients with recurrent ovarian cancer were suggested by the DESKTOP trial: i) Good PS, ii) no or small volume of ascites at recurrence, and iii) no gross residual disease after primary surgery (14). Another study suggested that the predictive factors for complete resection at SDS included FIGO stage, complete primary surgery, PFI, PS, CA125 value at recurrence and ascites at recurrence (15). In the present study, none of the patients who underwent SDS had ascites, but some patients who had not met these criteria still achieved long-term survival. It is suggested that the selection of candidates for SDS requires further discussion.

The response to chemotherapy after recurrence also affected OS after recurrence. The response rates to second-line chemotherapy are generally different according to the platinum-sensitivity status: $20-25 \%$ for platinum-sensitive cases, and $10-20 \%$ for platinum-resistant cases $(16,17)$. Our results suggested that the patients who exhibited complete or partial response to second-line regimens may become LS. Additionally, multiple lines of chemotherapy after recurrence also affected the PPS. Previous studies suggested the effectiveness of multiple lines of chemotherapy in ovarian cancer $(18,19)$. This fact may be associated with homologous recombinant deficiency (HRD), as HRD has been suggested to be associated with chemosensitivity and longer OS (20). Generally, the duration of response to second-line regimens is shorter compared with that of primary chemotherapy (1). However, patients with recurrent disease may achieve longer OS by receiving several lines of chemotherapy. Hoskins et al reported that some selected patients based on PS and interval of chemotherapy may benefit from successive chemotherapy (18). Further studies are required to confirm the effectiveness of multiple lines of chemotherapy.

In conclusion, three factors favouring long PPS in ovarian cancer were identified, namely SDS, favourable response to second-line chemotherapy and $\geq 3$ chemotherapy regimens after the first recurrence. Appropriate post-recurrence treatment is crucial for longer PPS. Although further analyses are required to evaluate the clinical significance of these factors, our study revealed potential clinicopathological markers favouring long-term PPS in recurrent ovarian cancer.

\section{References}

1. Ozols RF: Systemic therapy for ovarian cancer: Current status and new treatment. Semin Oncol 33 (2 Suppl 6): S3-S11, 2006.

2. Sundar S, Wu J, Hillaby K, Yap J and Lilford R: A systematic review evaluating the relationship between progression free survival and post progression survival in advanced ovarian cancer. Gynecol Oncol 125: 493-499, 2012.

3. van der Burg ME, de Wit R, van Putten WL, Logmans A, Kruit WH, Stoter G and Verweij J: Weekly cisplatin and daily oral etoposide is highly effective in platinum pretreated ovarian cancer. Br J Cancer 86: 19-25, 2002.

4. Zang RY, Zhand ZY, Li ZT, Cai SM, Tang MQ, Chen J and Liu Q: Impact of secondary cytoreductive surgery on survival of patients with advanced epithelial ovarian cancer. Eur J Surg Oncol 26: 798-804, 2000

5. Eisenhauer EA, Therasse P, Bogaerts J, Schwartz LH, Sargent D, Ford R, Dancey J, Arbuck S, Gwyther S, Mooney M, et al: New response evaluation criteria in solid tumours: Revised RECIST guideline (version 1.1). Eur J Cancer 45: 228-247, 2009.
6. Rustin GJ, Vergote I, Eisenhauer E, Pujade-Lauraine E, Quinn M, Thigpen T, du Bois A, Kristensen G, Jakobsen A, Sagae S, et al: Definitions for response and progression in ovarian cancer clinical trials incorporating RECIST 1.1 and CA 125 agreed by the Gynecological Cancer Intergroup (GCIG). Int J Gynecol Cancer 21: 419-423, 2011.

7. Shimokawa M, Ohki M and Kaku T: Correlation of progression-free and post-progression survival with overall survival in phase III trials of first-line chemotherapy for advanced epithelial ovarian cancer. Eur J Gynaecol Oncol 36: 370-375, 2015.

8. Vidal F, Guerby P, Luyckx M, Haddad P, Stoeckle E, Morice P, Leblanc E, Lecuru F, Daraï E, Classe JM, et al: Are early relapses in advanced-stage ovarian cancer doomed to a poor prognosis? PLoS One 11: e0147787, 2016.

9. Petrillo M, Pedone Anchora L, Tortorella L, Fanfani F, Gallotta V, Pacciani M, Scambia G and Fagotti A: Secondary cytoreductive surgery in patients with isolated platinum-resistant recurrent ovarian cancer: A retrospective analysis. Gynecol Oncol 134: 257-261, 2014.

10. Bristow RE, Puri I and Chi DS: Cytoreductive surgery for recurrent ovarian cancer: A meta-analysis. Gynecol Oncol 112: 265-274, 2009.

11. Salani R, Santillan A, Zahurak ML, Giuntoli RL II, Gardner GJ, Armstrong DK and Bristow RE: Secondary cytoreductive surgery for localized, recurrent epithelial ovarian cancer: Analysis of prognostic factors and survival outcome. Cancer 109: 685-691, 2007.

12. Laas E, Luyckx M, De Cuypere M, Selle F, Daraï E, Querleu D, Rouzier R and Chéreau E: Secondary complete cytoreduction in recurrent ovarian cancer: Benefit of optimal patient selection using scoring system. Int J Gynecol Cancer 24: 238-246, 2014.

13. van de Laar R, Massuger LF, Van Gorp T, IntHout J, Zusterzeel PL and Kruitwagen RF: External validation of two prediction models of complete secondary cytoreductive surgery in patients with recurrent epithelial ovarian cancer. Gynecol Oncol 137: 210-215, 2015.

14. Harter P, du Bois A, Hahmann M, Hasenburg A, Burges A, Loibl S, Gropp M, Huober J, Fink D, Schröder W, et al: Surgery in recurrent ovarian cancer: The arbeitsgemeinchaft gynaekologische onkologie (AGO) DESKTOP OVAR trial. Ann Surg Oncol 13: 1702-1710, 2006.

15. Tian WJ, Chi DS, Sehouli J, Tropé CG, Jiang R, Ayhan A, Cormio G, Xing Y, Breitbach GP, Braicu EI, et al: A risk model for secondary cytoreductive surgery in recurrent ovarian cancer: An evidence-based proposal for patient selection. Ann Surg Oncol 19: 597-604, 2012.

16. Vergote IB, Garcia A, Micha J, Pippitt C, Bendell J, Spitz D, Reed N, Dark G, Fracasso PM, Ibrahim EN, et al: Randomized multicenter phase II trial comparing two schedules of etirinotecan pegol (NKTR-102) in women with recurrent platinum-resistant/refractory epithelial ovarian cancer. J Clin Oncol 31: 4060-4066, 2013.

17. Markman M, Markman J, Webster K, Zanotti K, Kulp B, Peterson G and Belinson J: Duration of response to second-line, platinum-based chemotherapy for ovarian cancer: Implications for patient management and clinical trial design. J Clin Oncol 22: 3120-3125, 2004

18. Hoskins PJ and Le N: Identifying patients unlikely to benefit from further chemotherapy: A descriptive study of outcome at each relapse in ovarian cancer. Gynecol Oncol 97: 862-869, 2005.

19. Griffiths RW, Zee YK, Evans S, Mitchell CL, Kumaran GC, Welch RS, Jayson GC, Clamp AR and Hasan J: Outcomes after multiple lines of chemotherapy for platinum-resistant epithelial cancers of the ovary, peritoneum, and fallopian tube. Int J Gynecol Cancer 21: 58-65, 2011.

20. Sun C, Li N, Ding D, Weng D, Meng L, Chen G and Ma D: The role of BRCA status on the prognosis of patients with epithelial ovarian cancer: A systematic review of the literature with a meta-analysis. PLoS One 9: e95285, 2014. 